\title{
Essential oils as tick repellents on clothing
}

\author{
Oliver Soutar $^{1} \cdot$ Freya Cohen $^{1} \cdot$ Richard Wall $^{1}$
}

Received: 27 June 2019 / Accepted: 24 September 2019 / Published online: 1 October 2019

(c) The Author(s) 2019

\begin{abstract}
Essential oils show promise as natural alternatives to synthetic tick repellents, but few studies have investigated their repellent efficacy in vivo or under field conditions. Here, blanket-drags and standardised walks were employed to evaluate tick acquisition by $1 \mathrm{~m}^{2}$ cotton blankets or cotton trousers, respectively, in woodland edge habitats of known high tick abundance. Blankets and trousers had been treated with one of 5\% oregano, rosemary, spearmint or thyme oils, 20\% DEET ( $N, N$-diethyl-3-methylbenzamide) (positive control) or ethanol excipient-only (negative control). The number of ticks present on the blankets or trousers differed significantly between treatments: spearmint oil treatments resulted in significantly fewer ticks than the negative controls for both blankets and trousers and significantly fewer ticks were present on the oregano oil treated blankets. For ticks that did attach to the trousers, the rate of drop off within 3 min was significantly higher for trousers treated with spearmint oil or thyme oil than ethanol, oregano oil and rosemary oil. No reduction in repellence was detected over a $24 \mathrm{~h}$ period between treatment and testing. The results suggest that $5 \%$ oregano and spearmint oils exhibit potential as natural clothing repellents, with an effective equivalence to $20 \%$ DEET.
\end{abstract}

Keywords Habitat · Ixodes · Personal-protection · Sampling · Tick-borne-disease · Vector

\section{Introduction}

Ticks act as vectors of a greater diversity of disease-causing pathogens of humans than any other arthropod (Ginsberg and Faulde 2008). The most common and widespread tick throughout Europe, Ixodes ricinus L., the castor bean or forest tick, is the dominant species of medical concern (Bonnet et al. 2013; Cull et al. 2018). In Europe, it is the vector of Borrelia burgdorferi s.l., the causal agent of Lyme disease, and tick-borne encephalitis, which respectively infect more than 100,000 and 3000 people annually (Pålsson et al. 2008). The development of more effective personal protection measures against tick attachment and biting would make an important contribution to reducing the incidence of tick-borne disease.

Oliver Soutar

os15821@my.bristol.ac.uk

1 School of Biological Sciences, University of Bristol, 24 Tyndall Avenue, Bristol, UK 
Arthropod repellents are an effective means for humans to protect themselves against tick bites (Piesman and Eisen 2008; Bissinger and Roe 2010; Pages et al. 2014). Repellents can be applied topically to skin, or to clothing. The majority of commercially-available tick repellents are synthetic molecules, of which DEET ( $N, N$-diethyl-3-methylbenzamide) is the most extensively used active ingredient (Bissinger and Roe 2010; Pages et al. 2014). However, concerns over its safety, efficacy and environmental impacts have been reported (Aquino et al. 2004; Herrington 2004; Katz et al. 2008; Bissinger and Roe 2010; Osimitz et al. 2010). Hence, biologically-based repellents, particularly the plant-derived essential oils, may constitute an appealing alternative (Bissinger and Roe 2010; Del Fabbro and Nazzi 2013; Benelli et al. 2016, 2018).

The prevention of tick bites is a prerequisite for the prevention of tick-borne-disease, and therefore repellents should be designed to prevent new infestations and stop ticks from biting. They work, generally, by producing an irritant effect which causes questing ticks to avoid treated clothing or skin completely, or to fall off soon after contact with the treated surface (Halos et al. 2012). This definition is akin to 'contact irritancy', defined by Grieco et al. (2007) for mosquito repellents, which has recently been used in the context of ticks (Eisen et al. 2017). In practice a repellent could also describe a compound that simply prevents acquired ticks from biting, although this form of repellency is rarely encountered (Halos et al. 2012).

Botanical essential oils are complex mixtures of 20-60 low-molecular weight metabolites produced by aromatic plants, typically characterised by two or three major terpene or terpenoid components (Bakkali et al. 2008). Numerous laboratory studies have highlighted the tick-repellent efficacy of different essential oils (e.g., Pålsson et al. 2008; El-Seedi et al. 2012; Štefanidesová et al. 2017) suggesting that they hold considerable potential for development as practical tick repellents. However, field investigations of repellency are currently very limited (Ellse and Wall 2013; Goode et al. 2018).

The aim of the present study was to investigate the tick-repellence of the essential oils of oregano (Origanum vulgare), rosemary (Rosmarinus officinalis), spearmint (Mentha spicata) and thyme (Thymus vulgaris), against I. ricinus under field conditions. A blanketdrag assay was used alongside walking samples, in which essential oils were applied to clothing, to assess the effects of application on tick acquisition and drop-off (Ginsberg and Ewing 1989). The study also considered the residual repellency of oils.

\section{Materials and methods}

\section{Essential Oil selection}

The essential oils used in this study were selected based on a literature search using Web of Science (v.5.31; 14.01.2019; https://clarivate.com/products/web-of-science/). A database was made based on the following criteria: (i) tick species; (ii) plant species; (iii) test formulation (pure essential oil, plant extract or blend); (iv) concentration of active ingredient(s); (v) type of bioassay; (vii) use of appropriate controls, statistical interpretation, sample size and methods. Information was collated from 34 original and relevant peer-reviewed articles to create a list of 82 plant species. A point-based system was then used to compare and rank plant-derived repellents within each study, with additional weighting if they had been found to be effective against I. ricinus, were used in a climbing assay or were tested under field conditions. This semi-quantitative approach was used to identify plant species that 
performed consistently across studies. Essential oils were further shortlisted by considering their practicality as clothing repellents, for example their commercial availability, cost, and potential to stain material. As a result, the oils of oregano, rosemary, spearmint and thyme were chosen for this investigation. All are within the family Lamiaceae.

\section{Treatments and sampling materials}

Steam-distilled, $100 \%$ pure essential oils (Naissance Trading \& Innovation, Neath, UK) were stored in darkness at $5{ }^{\circ} \mathrm{C}$ to prevent thermo-degradation and oxidation. Essential oils were diluted in ethanol ( $\geq 99.8 \%$; VWR, Lutterworth, UK) to a concentration of $5 \%(\mathrm{v} / \mathrm{v})$. Ethanol only was used as a negative control. DEET (,$N$-Diethyl-3-methylbenzamide $97 \%$; Sigma-Aldrich, Gillingham, UK), diluted in ethanol to a concentration of $20 \%(\mathrm{v} / \mathrm{v})$, was used as a positive control (Frances 2007).

Ticks were sampled in two ways using unbleached $100 \%$ cotton calico cloth (J.D. McDougall, London, UK). The first collection technique used a $1 \mathrm{~m}^{2}$ blanket attached to a wooden pole $120 \mathrm{~cm}$ length, to which a string handle was tied and which was dragged slowly over the ground. Ticks were also acquired using trouser legs, made from the same calico material, with each leg measuring $80 \times 55 \mathrm{~cm}$ when opened flat and then sewn down one edge to form a tube. During tick sampling two trouser legs were worn by one of the investigators undertaking a standardised walk.

Prior to tick collection each day, treatments were sprayed onto blankets and trousers in a fume-cupboard using a pump-action spray bottle. The order of spray treatments was randomised. Each blanket was sprayed 30 times on one side only, at one pump approximately every $17 \times 20 \mathrm{~cm}$. Trousers were sprayed 14 times on each leg to achieve complete coverage. Each pump of the spray delivered a volume that had been measured volumetrically as delivering $1.1 \mathrm{ml}$, resulting in approximately $33 \mathrm{ml}$ and $30.8 \mathrm{ml}$ of solution being applied to each blanket and pair of trouser legs respectively. Following spraying, blankets and trouser legs were dried for $15 \mathrm{~min}$, to allow the ethanol to evaporate, before being sealed in individual airtight bags for transport to the field.

\section{Study area}

Field trials were conducted in Ashton Court Estate, a peri-urban public park to the west of the city of Bristol in south west England, which is inhabited by populations of managed and wild deer. The area has previously been shown to harbour large populations of I. ricinus (Jennett et al. 2013). Field trials were conducted in edge habitat, defined here as vegetation within $7.5 \mathrm{~m}$ of woodland edge. Prior to sampling, 19 relatively discrete $4 \times 30 \mathrm{~m}$ patches of suitable edge habitat were identified. Patches were selected based on the presence of matching vegetation type and height. All sampling occurred during February and March 2019.

\section{Repellency trials}

The nineteen edge habitat patches were each divided into six $2 \times 10 \mathrm{~m}$ sections and marked out with flags. In each section, a $10 \mathrm{~m}$ standardised straight-line walk was completed for one randomly allocated treatment (4 oils and 2 controls) and no vegetation was re-sampled. All treatments were tested once in each patch. During the standardised $10 \mathrm{~m}$ walk, 
the blanket was placed flat on the vegetation, treated-side face down, and dragged slowly (Jaenson et al. 2006). The investigator also wore trouser legs, which had received the same treatment as the blanket. The blanket was held behind and to the side of the investigator during the walk, so that the trousers and blanket did not sample the same vegetation. At the end of the walk, the blanket was turned over and the ticks on the blanket and trouser legs were counted by a second investigator. Only nymphs were counted, as these were abundant at this time of the year and are considered to be the most epidemiologically important ageclass from a human perspective (Clover and Lane 1995). Previous work has shown I. ricinus to be the only species collected in this area using these sampling techniques (Jennett et al. 2013). Three minutes after the first count, the ticks remaining on the trousers were re-counted to determine how many had dropped off. Ticks were then removed and returned to the vegetation. The order of sampling the different sites, and the sections within them, were randomised. All trials were completed between 12:00 and 17:30 h GMT, and each set of blanket and trouser legs was used only once.

At the start and end of sampling at each site, wind speed, cloud cover and precipitation were recorded. Throughout sampling, temperature and relative humidity at $30 \mathrm{~cm}$ above ground was recorded using an EL-USB-2 data logger (Lascar Electronics, Salisbury, UK). These factors were recorded to allow investigators to determine that weather conditions were similar on each sampling occasion.

\section{Residual repellency}

Based on the results of the repellency field trials, oregano and spearmint oils were selected to compare their residual activity alongside that of DEET. Treatment application and sampling followed the procedures described above, except that all materials were sprayed, then air-dried for $15 \mathrm{~min}$ before being placed in individual airtight bags, which were either sealed immediately $(0 \mathrm{~h}$ time period), or left open for 8,16 , or $24 \mathrm{~h}$ before being sealed and transported to the field. The vegetation patches used previously were re-used, but with patch sizes of $2 \times 40 \mathrm{~m}$ divided into four $2 \times 10 \mathrm{~m}$ sections. Each sampling site was randomly assigned to a drying-time period (11 replicates per drying-time). At each site, all spray treatments of the relevant time period were sampled by conducting a $10 \mathrm{~m}$ blanketdrag and walk in each section, as described above. There were no instances of investigators being bitten by ticks during the course of sampling.

\section{Statistical analysis}

All analyses were conducted using R Studio (v1.1.463, RStudio Team, 2016). Data from one sampling site in the repellency trials were removed because of rain, which affects the sampling effectiveness of cloth. There were no other major weather changes between sampling attempts in each patch. Due to the overdispersed nature of the data, negative binomial regressions were conducted to investigate differences between treatments in the number of ticks acquired by blankets and trousers. Comparison to the null model was made using a $\chi^{2}$ likelihood ratio test, to evaluate whether treatment was a significant predictor of the number of ticks counted. Post-hoc pairwise comparisons of the estimated marginal means, with Tukey-adjusted P-values, were used to identify significant differences in tick numbers between treatments. A further binomial generalized linear model (GLM) was used to examine whether the percentage of ticks that dropped off trousers in the 3 min following walks differed between treatments. 
For the residual repellency trials, data from two samples were omitted from analysis due to rain during sampling. There were no major weather changes between the remaining sampling attempts in each patch. Two negative binomial regressions were used to examine the effects of treatment, drying-time, and the interaction between treatment and dryingtime, on the numbers of ticks on blankets and trousers separately. In each case, a backwards model selection approach was employed to remove non-significant predictors from the full model. Chi squared likelihood ratio tests were used to compare nested models and identify non-significant predictors of tick acquisition at each step. Post-hoc pairwise comparisons of the estimated marginal means, with Tukey-adjusted P-values, were used to identify significant differences in the number of ticks counted between treatments.

\section{Results}

\section{Repellency trials}

In total, 1385 ticks were found on blankets immediately following blanket-drags, with a median per drag of 5.5 (interquartile range [IQR]: 11.75) for DEET $(n=18), 29$ (IQR: 24.25) for ethanol $(n=18), 4$ (IQR: 7) for oregano oil $(n=17), 11$ (IQR: 28) for rosemary oil $(\mathrm{n}=17), 2$ (IQR: 5$)$ for spearmint oil $(\mathrm{n}=18)$, and 5 (IQR: 7.25$)$ for thyme oil $(\mathrm{n}=18)$ (Fig. 1a). Overall, there was a significant difference between treatments in the number of ticks counted on blankets $\left(\chi_{(5)}^{2}=26.16, P<0.001\right)$, with post hoc tests showing that significantly more ticks were found on blankets treated with ethanol only than those treated with DEET $(P=0.008)$, oregano oil $(P=0.010)$, or spearmint oil $(P<0.001)$. Significantly fewer ticks were found on spearmint oil-treated blankets than on rosemary oil-treated blankets $(P=0.010)$. All other comparisons between treatments were non-significant $(P>0.05$; Fig. 1a).
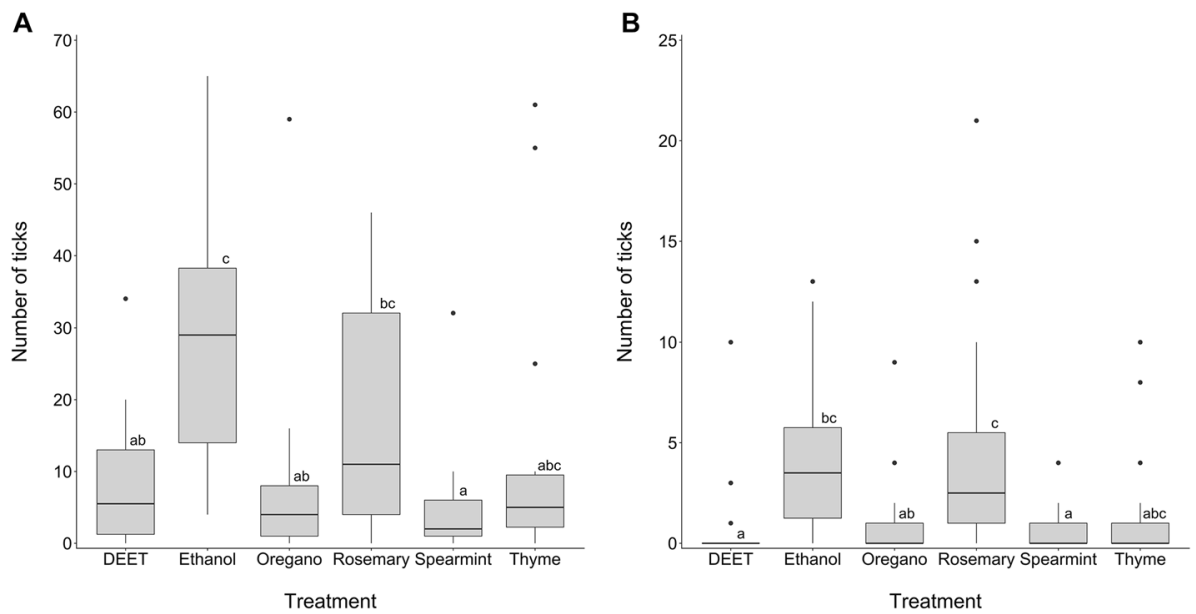

Fig. 1 The number of Ixodes ricinus ticks acquired by: a blankets and b trousers treated with DEET, ethanol, oregano oil, rosemary oil, spearmint oil or thyme oil in repellency trials, showing the median (horizontal bar), interquartile range (IQR; box), first data point within $1.5 \times$ the IQR of the 1 st and 3 rd quartile (vertical lines), and outliers (dots). Different letters within a panel denote statistically significant differences among treatments 
In total, 243 ticks were counted on trousers following walks, with a median number of ticks per walk of 0 (IQR: 0$)$ for DEET $(n=18), 3.5$ (IQR: 4.5$)$ for ethanol only $(n=18), 0$ (IQR: 1) for oregano oil $(n=18), 2.5$ (IQR: 4.5) for rosemary oil $(n=18), 0$ (IQR: 1) for spearmint oil $(\mathrm{n}=18)$, and 0 (IQR: 1$)$ for thyme oil $(\mathrm{n}=18)$ (Fig. 1b). The number of ticks recorded on trousers differed significantly between treatments $\left(\chi_{(5)}^{2}=24.68, P<0.001\right)$, with post hoc tests showing significantly higher numbers of ticks on trousers treated with ethanol only than for trousers treated with DEET $(P=0.030)$ or spearmint oil $(P=0.004)$. Similarly, the number of ticks found on trousers treated with rosemary oil was higher than the number found on trousers treated with DEET $(P=0.014)$ or spearmint $(P=0.001)$. All other comparisons between treatments were non-significant $(P>0.05)$ (Fig. 1b).

In the 3 min following walks, the numbers of ticks that subsequently dropped off of the trousers was 11 out of $17(64.7 \%)$ for DEET, 35 out of $79(44.3 \%)$ for ethanol, 9 out of $20(45 \%)$ for oregano oil, 34 out of $89(38.2 \%)$ for rosemary oil, 7 out of $11(63.6 \%)$ for spearmint oil, and 19 out of 27 (70.4\%) for thyme oil (Fig. 2). The percentage of acquired ticks that dropped from trousers differed significantly between treatments $\left(\chi_{(5)}^{2}=12.47\right.$, $P=0.029$ ) with ethanol, oregano oil and rosemary oil showing a lower rate of drop-off compared to DEET, spearmint oil or thyme oil (Fig. 2).

\section{Residual repellency}

For blankets, both drying time period (coefficient $=-0.03$, S.E. $=0.01, \quad \chi_{(1)}^{2}=7.20$, $P=0.007)$ and treatment $\left(\chi_{(3)}^{2}=63.64, P<0.001\right)$ were shown by the negative binomial regression model $(\Delta$ deviance $=189.7$, d.f. $=163)$ to be significant predictors of the number of ticks counted following sampling. However, the interaction between drying time and treatment type was not significant $\left(\chi_{(5)}^{2}=4.59, P=0.21\right)$, suggesting that the effect of

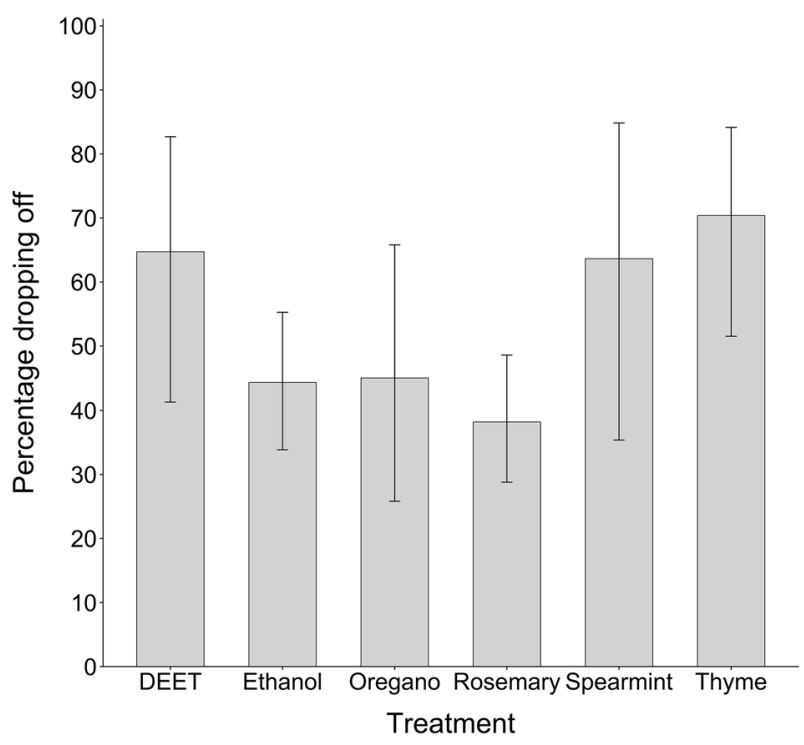

Fig. 2 The percentage of Ixodes ricinus ticks that dropped off trousers treated with ethanol, DEET, oregano oil, rosemary oil, spearmint oil or thyme oil in the 3 min after being acquired (with $95 \%$ Wilson binomial confidence intervals) 
treatment on the numbers of ticks was not dependent on the length of drying time. Subsequent post hoc tests showed that greater numbers of ticks were found on ethanol-treated blankets than on DEET-treated $(P<0.001)$, oregano oil-treated $(P<0.001)$, or spearmint oil-treated $(P<0.001)$ blankets. All other comparisons between treatments were non-significant $(\mathrm{P}>0.05)$ (Fig. 3a).

For trousers, negative binomial regression $(\Delta$ deviance $=156.2$, d.f. $=163)$ again found that both drying time period (coefficient $=-0.049$, S.E. $=0.016, \chi_{(1)}^{2}=9.67, P=0.002$ ) and treatment $\left(\chi_{(5)}^{2}=41.59, P<0.001\right)$ were significant predictors of tick acquisition following walks. In addition, the interaction between drying time period and treatment was again non-significant $\left(\chi_{(5)}^{2}=3.90, P=0.27\right)$, suggesting that differences in tick acquisition between treatments were independent of drying time. A greater number of ticks were counted on trousers treated with ethanol than those treated with DEET $(P=0.001)$, oregano oil $(P<0.001)$, or spearmint oil $(P<0.001)$. All other comparisons between treatments were non-significant $(P>0.05)$ (Fig. 3b).

\section{Discussion}

If tick-infested habitat cannot be avoided, the use of repellents, particularly in conjunction with other protective measures, may make an effective contribution to reducing the risk of tick bites and subsequent TBD transmission (Piesman and Eisen 2008; Benelli and Pavela 2018). Here, at 5\% (v/v), spearmint and oregano oils demonstrated repellence comparable to $20 \%$ DEET over a period of $24 \mathrm{~h}$, suggesting that they hold considerable potential as clothing repellents. Rosemary oil-treated materials were ineffective when compared to DEET-treated materials, supporting the conclusion that the effect of spearmint and oregano oils is likely to have been due to their volatile essential oil components rather than any mechanical oil-related activity. In studies where all oils tested appear to be effective, but no non-essential control is used, the mode of action cannot be resolved (Ellse and Wall 2013).
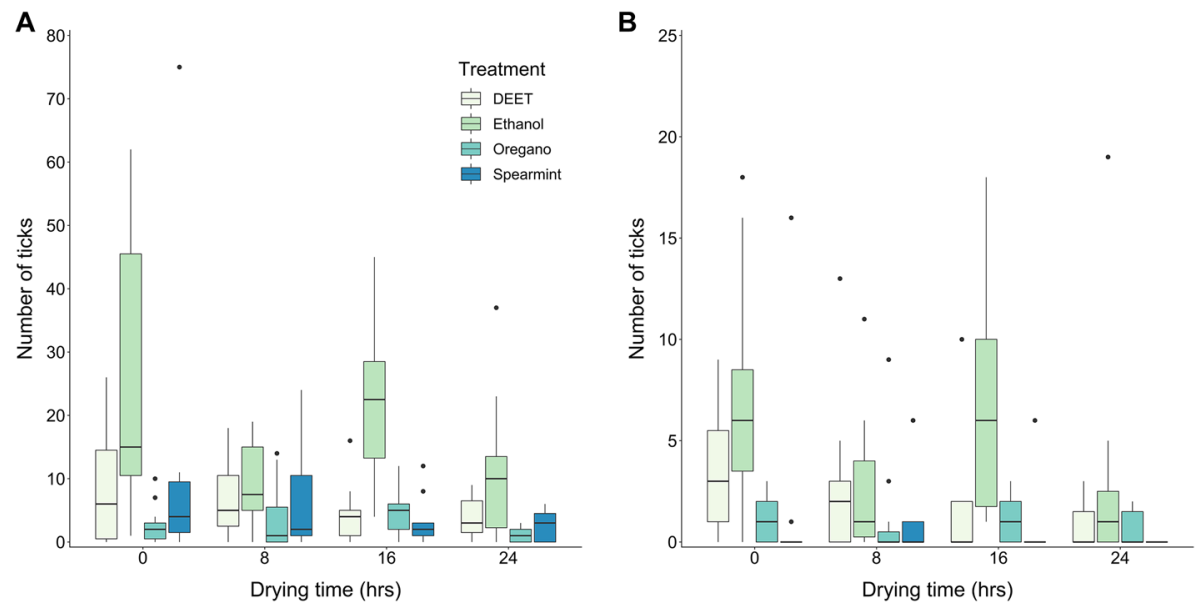

Fig. 3 The number of ticks acquired by: $\mathbf{a}$ blankets and $\mathbf{b}$ trousers treated with DEET, ethanol, oregano oil or spearmint oil for each drying time (h) during residual repellency trials, showing the median (horizontal bar), interquartile range (IQR; box), first data point within $1.5 \times$ the IQR of the 1 st and 3rd quartile (vertical lines) and outliers (dots) 
The repellency of various essential oils to ticks has been demonstrated previously. In a laboratory bioassay, $5 \%(\mathrm{v} / \mathrm{v})$ spearmint oil was shown to inhibit the natural climbing behaviour of $100 \%$ of I. ricinus on which it was tested (Goode et al. 2018). Separately, El-Seedi et al. (2012) applied spearmint oil at $15 \mu \mathrm{g} / \mathrm{cm}^{2}$ to cloths fixed over vials; $89.5 \%$ of ticks within vials were repelled after 5 min. During subsequent blanket-drag trials, spearmint oil demonstrated $59.4 \%$ repellency in comparison to an excipient-only solution. In laboratory bioassays, thyme oil has demonstrated $68.2 \%$ repellency at $3 \%(\mathrm{v} / \mathrm{v})$ and $100 \%$ repellency at $5 \%(\mathrm{v} / \mathrm{v})$ against Dermacentor reticulatus and I. ricinus, respectively (Štefanidesová et al. 2017; Goode et al. 2018). However, field trails are relatively rare; turmeric oil was shown to be both able to prevent the attachment of ticks to impregnated blankets and to significantly reduce the rate of tick acquisition by dogs sprayed before each walk, in known tick-infested areas (Goode et al. 2018).

In the present study, blanket-drags were accompanied by walking samples in tickinfested habitat, in which tick attachment to oil-treated trousers was compared to an excipient-only control. As such, the trials constituted what Bissinger and Roe (2010) consider to be an optimum test of repellency. During the repellency field trials, tick attachment to blankets and trousers was significantly lower for 5\% spearmint and oregano oils than for the excipient-only solution; spearmint oil demonstrated repellency of greater than $80 \%$ on both blankets and trousers. The walking samples employed here provide a valuable measure of repellency, as trousers present host cues (e.g., heat and $\mathrm{CO}_{2}$ ) that blankets do not, and repellency may be overestimated if host cues are absent (Dautel 2004).

Previous studies have suggested that the use of essential oils in vector and ectoparasite control may be limited by their high volatility and short residual activity. For example, separate investigations into the acaricidal activities of cinnamon and lavender oil on mites both reported reduced mortality when treatments were subjected to an extended drying period before being tested (George et al. 2008; Wall and Bates 2011). However, the repellent efficacy of essential oils may outlast their acaricidal activity (Ellse and Wall 2013). Here, no significant decline in residual repellency of 5\% spearmint and oregano oil was detected for blankets and trousers over a $24 \mathrm{~h}$ period following oil application, showing that 5\% spearmint and oregano oils impart protection against I. ricinus for an extended period post-application. Previous work has shown thyme oil to maintain $100 \%$ repellency against $I$. ricinus after $1 \mathrm{~h}$ of drying (Goode et al. 2018).

Oil treated blankets have previously demonstrated repellency over two consecutive days of sampling when blankets were placed in sealed plastic-bags between each fieldwork day (El-Seedi et al. 2012). Here, treated materials were placed in plastic bags over $24 \mathrm{~h}$ following treatment although these were not sealed, providing greater opportunity for the oil components to evaporate. Despite this, evaporation may still not have occurred at the rate expected during practical usage. Materials were dried in the laboratory under near-constant conditions, whereas repellents applied to clothing in the field are exposed to variable conditions such as wind and humidity that can influence evaporation rate and thus repellency (Bissinger and Roe 2010). In future studies, a method of drying that better reproduces field conditions, either by keeping materials outside for the desired period or by reconstructing 'natural' conditions in a laboratory setting (e.g., George et al. 2008), may therefore constitute a more rigorous assessment of residual repellency.

In both experiments reported here, spearmint and oregano oil performed comparably to $20 \%$ DEET. Products containing DEET at this concentration are typically marketed for use in non-tropical destinations, although unlike these products, here pure DEET was simply diluted in ethanol. The tick repellent efficacy of DEET is dependent on its formulation (Salafsky et al. 2000), and the correct formulation of a repellent serves to maximise its 
effectiveness (Bissinger and Roe 2010). Hence, it is possible that the DEET in this study may have had lower repellency compared to a formulated commercial product. The essential oils investigated here were similarly un-formulated, however, and thus comparison to the DEET solution used was considered an appropriate evaluation of their efficacy. The development of appropriate essential oil-based formulations is an important next step in optimizing their efficacy (Bissinger and Roe 2010; Ellse and Wall 2013), after which comparisons to existing, commercially-available, synthetic formulations will be necessary to fully evaluate their potential as commercial products. It should also be noted that few human safety studies have been conducted on these essential oils, although since $5 \%$ dilutions were used in this study, few problems might be anticipated.

For those ticks that did attach to trousers in the present study, the drop off rate was higher for materials impregnated with thyme and spearmint oils than with rosemary, oregano or ethanol only and the drop off rates were equivalent to those seen with $20 \%$ DEET. Whilst further investigation into their modes of action would be useful, these data nonetheless suggest that the essential oils demonstrated repellency at two stages in the host acquisition process.

Across both experiments, attachment to excipient-only blankets averaged 25.2 $(\mathrm{SD} \pm 26.2)$ ticks per $10 \mathrm{~m}$ walk, which is comparable to the results reported for previous sampling efforts in similar habitat at this site (Goode et al. 2018). The tick counts on trousers give a better indication of the risk to humans of walking in these habitats than analyses based on blanket-dragging alone, and for trousers attachment averaged 6.2 ( $\mathrm{SD} \pm 10.2$ ) ticks per $10 \mathrm{~m}$ walk. The lower attachment rate for trousers, despite the presence of hostspecific cues, relates to the smaller area of contact between cloth and vegetation. Trials in the present study occurred from February to March; the activity of I. ricinus nymphs in UK sites has been found to increase from March to a peak in May (Randolph et al. 2002; Jennett et al. 2013), and so these encounter rates may be conservative in comparison to subsequent months. These data, therefore, highlight the relatively high risk of tick bite when walking in these sites at this time of year. A spearmint or oregano oil-based repellent could form an affordable and appealing alternative for people unwilling to use DEET or other synthetic repellents. To fully realise this potential, further field trials are required to evaluate formulations and identify those that provide maximum efficacy.

Acknowledgements This research was funded by the University of Bristol. We are grateful to Carrie Wierszycki, Val Soutar and Libby Soutar for their generous contribution to the production of fieldwork materials.

Open Access This article is distributed under the terms of the Creative Commons Attribution 4.0 International License (http://creativecommons.org/licenses/by/4.0/), which permits unrestricted use, distribution, and reproduction in any medium, provided you give appropriate credit to the original author(s) and the source, provide a link to the Creative Commons license, and indicate if changes were made.

\section{References}

Aquino M, Fyfe M, MacDougall L, Remple V (2004) West nile virus in British Columbia. Emerg Infect Dis 10:1499-1501

Bakkali F, Averbeck S, Averbeck D, Idaomar M (2008) Biological effects of essential oils: a review. Food Chem Toxicol 46:446-475

Benelli G, Pavela R (2018) Repellence of essential oils and selected compounds against ticks: a systematic review. Acta Trop 179:47-54 
Benelli G, Pavela R, Canale A, Mehlhorn H (2016) Tick repellents and acaricides of botanical origin: a green roadmap to control tick-borne diseases? Parasitol Res 115:2545-2560

Bissinger B, Roe R (2010) Tick repellents: past, present, and future. Pestic Biochem Physiol 96:63-79

Bonnet S, de la Fuente J, Nicollet P et al (2013) Prevalence of tick-borne pathogens in adult Dermacentor spp. ticks from nine collection sites in France. Vector-Borne Zoonotic Dis 13:226-236

Clover JR, Lane RS (1995) Evidence implicating nymphal Ixodes pacificus (Acari: Ixodidae) in the epidemiology of Lyme disease in California. Am J Trop Med Hyg 53:237-240

Cull B, Pietzsch M, Hansford K, Gillingham E, Medlock J (2018) Surveillance of British ticks: an overview of species records, host associations, and new records of Ixodes ricinus distribution. Ticks Tick-borne Dis 9:605-614

Dautel H (2004) Test systems for tick repellents. Int J Med Microbiol Suppl 293:182-188

Del Fabbro S, Nazzi F (2013) From chemistry to behavior Molecular structure and bioactivity of repellents against Ixodes ricinus ticks. PLoS ONE 8:e67832

Eisen L, Rose D, Prose R, Breuner N, Dolan M, Thompson K, Connally N (2017) Bioassays to evaluate non-contact spatial repellency, contact irritancy, and acute toxicity of permethrin-treated clothing against nymphal Ixodes scapularis ticks. Ticks Tick-borne Dis 8:837-849

Ellse L, Wall R (2013) The use of essential oils in veterinary ectoparasite control: a review. Med Vet Entomol 28:233-243

El-Seedi H, Khalil N, Azeem M, Taher E, Göransson U, Pålsson K, Borg-Karlson A (2012) Chemical composition and repellency of essential oils from four medicinal plants against Ixodes ricinus nymphs (Acari: Ixodidae). J Med Entomol 49:1067-1075

Frances S (2007) Efficacy and safety of repellents containing DEET. In: Debboun M, Frances S, Strickman D (eds) Insect repellents: principles, methods, and uses, 1st edn. CRC Press, Boca Raton, pp 311-326

George D, Callaghan K, Guy J, Sparagano O (2008) Lack of prolonged activity of lavender essential oils as acaricides against the poultry red mite (Dermanyssus gallinae) under laboratory conditions. Res Vet Sci 85:540-542

Ginsberg H, Ewing C (1989) Comparison of flagging, walking, trapping, and collecting from hosts as sampling methods for northern deer ticks, Ixodes dammini, and lone-star ticks, Amblyomma americanum (Acari: Ixodidae). Exp Appl Acarol 7:313-322

Ginsberg H, Faulde M (2008) Ticks. In: Bonnefoy X, Kampen H, Sweeney K (eds) Public health significance of urban pests, 1st edn. World Health Organization, Copenhagen, pp 304-345

Goode P, Ellse L, Wall R (2018) Preventing tick attachment to dogs using essential oils. Ticks Tick-Borne Dis 9:921-926

Grieco J, Achee N, Chareonviriyaphap T, Suwonkerd W, Chauhan K, Sardelis M, Roberts D (2007) A new classification system for the actions of IRS chemicals traditionally used for malaria control. PLoS ONE 2:e716

Halos L, Baneth G, Beugnet F et al (2012) Defining the concept of 'tick repellency' in veterinary medicine. Parasitol 139:419-423

Herrington J (2004) Risk perceptions regarding ticks and Lyme disease: a national survey. Am J Prev Med 26:135-140

Jaenson T, Garboui S, Pålsson K (2006) Repellency of oils of lemon eucalyptus, geranium, and lavender and the mosquito repellent MyggA natural to Ixodes ricinus (Acari: Ixodidae) in the laboratory and field. J Med Entomol 43:731-736

Jennett A, Smith F, Wall R (2013) Tick infestation risk for dogs in a peri-urban park. Parasites Vectors 6:358

Katz T, Miller J, Hebert A (2008) Insect repellents: historical perspectives and new developments. J Am Acad Dermatol 58:865-871

Osimitz T, Murphy J, Fell L, Page B (2010) Adverse events associated with the use of insect repellents containing $N, N$-diethyl-m-toluamide (DEET). Regul Toxicol Pharmacol 56:93-99

Pages F, Dautel H, Duvallet G, Kahl O, de Gentile L, Boulanger N (2014) Tick repellents for human use: prevention of tick bites and tick-borne diseases. Vector-borne Zoonotic Dis 14:85-93

Pålsson K, Jaenson T, Bæckström P, Borg-Karlson A (2008) Tick repellent substances in the essential oil of Tanacetum vulgare. J Med Entomol 45:88-93

Piesman J, Eisen L (2008) Prevention of tick-borne diseases. Annu Rev Entomol 53:323-343

Randolph S, Green R, Hoodless A, Peacey M (2002) An empirical quantitative framework for the seasonal population dynamics of the tick Ixodes ricinus. Int J Parasitol 32:979-989

Salafsky B, He Y, Li J, Shibuya T, Ramaswamy K (2000) Short report: study on the efficacy of a new longacting formulation of $\mathrm{N}, \mathrm{N}$-diethyl-m-toluamide (DEET) for the prevention of tick attachment. Am J Trop Med Hyg 62:169-172

Štefanidesová K, Śkultéty L', Sparagano O, Špitalská E (2017) The repellent efficacy of eleven essential oils against adult Dermacentor reticulatus ticks. Ticks Tick-Borne Dis 8:780-786 
Wall R, Bates P (2011) Sheep scab control using trans-cinnamic acid. Vet Parasitol 175:129-134

Publisher's Note Springer Nature remains neutral with regard to jurisdictional claims in published maps and institutional affiliations. 